\title{
The Effect of Baffle Inclination on a Heat Recovery Ventilator Performance
}

\author{
Hawraa Imad Abdulhafedh ${ }^{1}$, Saadoon Fahad Albahadili ${ }^{2}$, Raed Sabri Hameed ${ }^{3}$ \\ \{eng_hawra5@yahoo.com ${ }^{1}$, s.albahadili@stu.edu.iq ${ }^{2}$, raed.hameed@stu.edu.iq ${ }^{3}$ \} \\ Engineering Technical College of Basra, Southern technical university, Basra, Iraq
}

\begin{abstract}
The current research focuses on numerical simulations of recovering low-grade airborne heat to co-save a portion of the energy used by household ventilation. The investigation of three-dimensional steady-state turbulent flow and heat transfer utilizing the CFD approach and the finite volume method with ANSYS software to solve the Naiver Stock and energy equations. The turbulent flow model is governed by the k- $\varepsilon$ turbulence model with the SIMPLE-discretization algorithm. To enhance the recovering system thermal performance, two baffles are inserted into both inlet hot and cold channels with changing their inclination $\left(45,90\right.$, and $\left.135^{\circ}\right)$ respectively. The Thermo aerodynamic performance assessments are included velocity, temperature, and effectiveness distribution along with airflow from the leading edge to the end of the core, through the two baffles. The results reveal simply that the flow is characterized by significant deformations. When fixed inclination baffles $\left(45^{\circ}\right)$ are added inside the channel at a constant Reynolds number, the efficacy increases by $35 \%$.
\end{abstract}

Keywords: Heat Recovery, Numerical Simulation, Plat heat exchangers, Baffles, CFD.

\section{Introduction}

Rapid increases in global energy consumption have raised questions about supply issues, energy depletion, and negative environmental consequences. Global change and ozone destruction, for example, have been major problems that people have had to contend with. Building energy consumption, including operation and maintenance, accounts for $40 \%$ of total global energy demand today. Furthermore, heating, ventilation, and air conditioning (HVAC) systems use 40-60 percent of a building's energy intake, depending on the environment. Meanwhile, this energy consumption results in a significant volume of greenhouse gas pollution, such as carbon dioxide emissions (CO2). As a result, governments are working to improve energy-efficient and environmentally sustainable construction technology. Because of their potential to deliver significant energy benefits for residential buildings, heat recovery systems are seen as a very promising technology. A heat recovery ventilator (HRV) is a heat recovery device that recovers heat from an air-to-air heat exchanger. It transfers heat or mass from one air stream to another by removing, recovering, or salvaging it. To put it another way, the air that would otherwise be discarded into the atmosphere is used to preheat or precool the incoming air of an HVAC device. Heat recovery systems usually recover 60 percent to 95 percent of the heat in the exhaust air, resulting in dramatic improvements in building energy efficiency [1]. 
A few studies have evaluated the potential of plate type on heat recovery performance. Han $\mathrm{H}$ et al [2] performed an experimental study to evaluate the influences of outdoor conditions variation on the thermal performance of the plate-type heat recovery ventilators. The results observed that the outdoor temperature decreasing as an enhancement influence on the heat recovery coil efficiencies.

Assuncao [1] did a simulation study to evaluate the influences of baffle geometry, and Reynolds number variation on the heat recovery ventilator performance. The results show that the height of the baffle has a positive influence on the overall ventilator performance. In the case of the Reynolds variations, the increase has the worst influences on the pressure drop, meanwhile, an augmented Nusselt number so as the heat transfer effectiveness. M.Ghazvini et al. [3] presented a simulation study to predict the influences of $\mathrm{V}$-fin attack angle on the performance of heat recovery system, under different flow and wide range of attack angle $\left(40^{\circ}-80^{\circ}\right)$. The study observed that under a high flow rate the attack angle of $40^{\circ}$ shows the highest system performance. Kang et al. [4] investigated the effect of porous baffles, experimentally, on the average heat transfer coefficients for heated rectangular channels made up of aluminum foam. The results showed that porous baffles have enhanced influences on heat transfer by $300 \%$ compared to straight channels with no baffles. Hamidou et al. [5] Introduced a numerical procedure to study the effect of wavy baffle using a rectangular duct section on heat transfer for turbulent flow. The baffle was arranged in the duct wall to produce vortices. They concluded that wavy baffles using will increase the velocity more than four times the reference velocity. D. Saad et al. [6] evaluated the effect of the baffle's shape inside a corrugated square duct experimentally. The study includes various baffles shape flat, rectangular, semicircular, triangular, and trapezoidal. The results show that the baffles using have an enhanced effect on the average Nusselt-number compared to the smooth duct, meanwhile baffles leads to a substantial increase in friction factor over a plain duct; the trapezoidal baffle provides higher thermal performance than the other baffled. Waleed et al. [7] presented a numerical study for the v-corrugated channel angles influences on laminar forced convection heat transfer and fluid flow characteristics with angles variations from $0^{\circ}$ to $60^{\circ}$. The results showed that the wavy angle increasing at constant Reynolds increases has an enhanced effect on heat transfer and pressure drop. The corrugated angle of 60 shows maximum heat transfer enhancement. Younes et al. [8] carried out a simulation analysis for cascaded rectangular-triangular baffle (CRTB) using FLUENT software. The results showed that the insertion of CRTBs in the channel has considerable enhancement on heat transfer rate meanwhile much high friction loss. Xinyi et al. [9] investigated experimentally and numerically the overall heat transfer performance and friction factor in a rectangular duct with ribbed and ribbed-grooved rib angle of $30^{\circ}$. With slopes angles of $30^{\circ}, 45^{\circ}, 60^{\circ}$, and $0^{\circ}$. The experimental results show that the grooved channel has enhanced positive influences on the overall thermal performance, the Nusselt number ratio, and the friction factor ratio. The numerical results show that the slope angles of $30^{\circ}$ and $45^{\circ}$ show superior thermal performance and overall thermo-hydraulic performance ratio compared with the cases for V-shape ribs. Y. Menni et al. [10] performed numerically the effect of complex obstacles within solar channels. Where two obstacles of the form ' + ' interlaced within a twodimensional and rectangular channel have been placed. A Newtonian fluid, turbulent, incompressible, and of stable properties flows inside the channel. The effect of flow rate on temperature was investigated. the fluid dynamic analysis showed a considerable augmentation in the normalized friction factor with the Reynolds number, introducing large recirculation zones. where it was found that direct proportionality between the skin friction and the elevation of the Reynolds number. Prashanta et al. [11] presented an experimental investigation of the effect of baffles characteristics (orientation, perforation, and position) on local heat transfer and 
friction factor in a rectangular duct. The study concluded that using two inclined baffles has a positive enhancement on both the overall heat transfer coefficient and the average Nusselt number compared to smooth duct, meanwhile having the worst effect on frictional head loss. To improve the performance of systems, Ameur [12] quantitatively evaluated the impact of the inclination angle of baffles and the direction of inclination on a rectangular channel heat exchanger. These studies discovered that the straight baffle produces a more intense and wider vortex than the inclined baffle. The opposite direction appears to be more promising in terms of heat transfer intensification in the case of the inclined baffle.

The purpose of this study is an enhancement of the turbulent heat transfer inside the plate-type (crossflow) heat recovery ventilator by installing two baffles along the airflow duct that are attached on the top and bottom sides of the hot and cold inlet ducts, as well as investigating three different baffle angles $\left(45^{\circ}, 90^{\circ}\right.$, and $135^{\circ}$ ).

The paper is structured as follows: the numerical model is proposed in section 2 followed by showing the obtained results for four case studies in section 3. Finally, the paper is concluded in section 4 .

\section{Numerical models}

HRV is visualized and simulated by numerical simulation using commercial CFD code by ANSYS Fluent version 20 program. The Fixed plate heat recovery system is the most widely used type, owing to the structure simplicity associated with efficiency enhancement. Which consist of thin plates stacked together. For better heat transfer, the plates may be flat, have baffles, or have other disturbances. [1]. The schematic of a crossflow fixed-plate heat recovery system with two channels with two baffles for both channels is shown in Fig. 1. with a heat exchanger dimension of $370 \mathrm{~mm}$ width(w), $320 \mathrm{~mm}$ height $(\mathrm{H})$, and $\mathrm{L}=370 \mathrm{~mm}$ in length and dimension of the cold and hot channel are $\mathrm{W}=370 \mathrm{~mm}$ in width, $\mathrm{H}=320 \mathrm{~mm}$ in height and $\mathrm{L}$ $=1170 \mathrm{~mm}$ in length. The baffles have a high $\mathrm{H}=137.28 \mathrm{~mm}$.

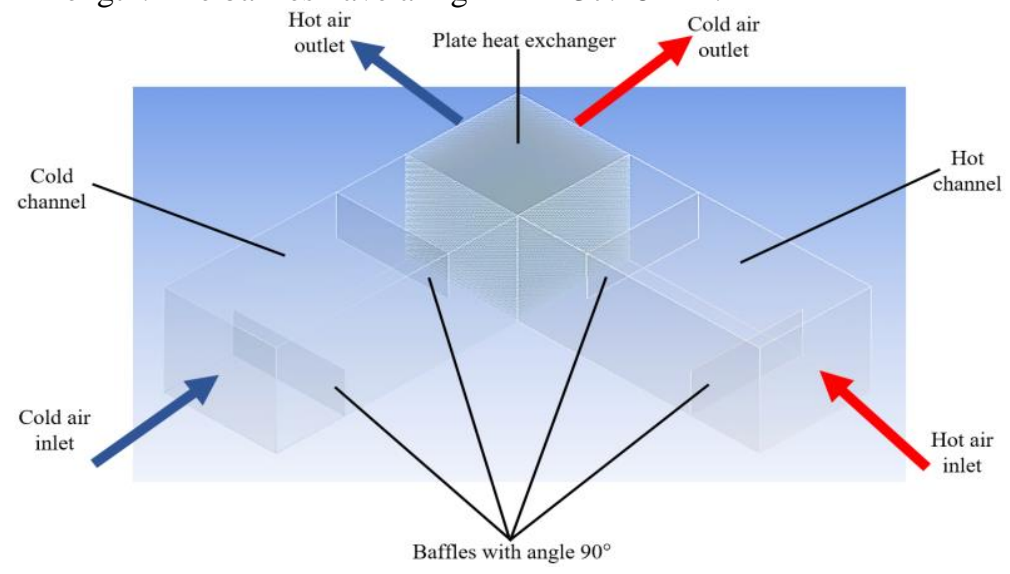

Fig. 1. The longitudinal section of the exchanger with hot and cold channels.

\subsection{Assumptions}


The current work uses the following:

- $\quad$ Reynolds number 12000 is used in the numerical simulation.

- The airflow should be turbulent and at a constant rate.

- Heat and flow transfer are three-dimensional processes.

- Gravity and radiation have no effect.

- $\quad$ Fluid and solid physical characteristics remain constant.

- The fluid is incompressible and Newtonian.

- The fluid has a steady velocity profile and a uniform temperature as it enters the channel; and

- The Shear-Stress Transport (SST) k-model is utilised to close the configuration under inquiry.

\subsection{Boundary conditions}

A uniform Three-dimensional profile of fluid velocity $(\mathrm{u}=\mathrm{Uin}, \mathrm{v}=\mathrm{Uin}, \mathrm{w}=\mathrm{Uin})$ at $25^{\circ} \mathrm{C}$ ( Tin $=298 \mathrm{~K})$ is in cold channel and $(\mathrm{u}=\mathrm{Uin}, \mathrm{v}=\mathrm{Uin}, \mathrm{w}=\mathrm{Uin})$ at $41^{\circ} \mathrm{C}(\mathrm{Tin}=314 \mathrm{~K})$ in hot channel. an atmospheric pressure $(\mathrm{P}=\mathrm{Patm})$ outlet condition is applied at the channel outlet. The inlet turbulence intensity was kept constant at $\mathrm{I}=2 \%$. Impermeable boundary and no-slip wall criteria were applied to the channel's surfaces.

\subsection{Governing equations}

The Continuity Equation:

$$
\frac{\partial \mathrm{u}}{\partial \mathrm{x}}+\frac{\partial \mathrm{v}}{\partial \mathrm{y}}+\frac{\partial \mathrm{w}}{\partial \mathrm{z}}=0
$$

The Momentum Equations:

X-Direction:

$$
\begin{gathered}
\rho\left(\mathrm{u} \frac{\partial \mathrm{u}}{\partial \mathrm{x}}+\mathrm{v} \frac{\partial \mathrm{u}}{\partial \mathrm{y}}+\mathrm{w} \frac{\partial \mathrm{u}}{\partial \mathrm{z}}\right)=-\frac{\partial \mathrm{P}}{\partial \mathrm{x}}+ \\
\mu\left(\frac{\partial^{2} \mathrm{u}}{\partial \mathrm{x}^{2}}+\frac{\partial^{2} \mathrm{u}}{\partial \mathrm{y}^{2}}+\frac{\partial^{2} \mathrm{u}}{\partial \mathrm{z}^{2}}\right)
\end{gathered}
$$

Y- Direction:

Z- Direction:

$$
\begin{gathered}
\rho\left(\mathrm{u} \frac{\partial \mathrm{v}}{\partial \mathrm{x}}+\mathrm{v} \frac{\partial \mathrm{v}}{\partial \mathrm{y}}+\mathrm{w} \frac{\partial \mathrm{v}}{\partial \mathrm{z}}\right)=-\frac{\partial \mathrm{P}}{\partial \mathrm{y}}+\rho \mathrm{g}_{\mathrm{y}}+ \\
\mu\left(\frac{\partial^{2} \mathrm{v}}{\partial \mathrm{x}^{2}}+\frac{\partial^{2} \mathrm{v}}{\partial \mathrm{y}^{2}}+\frac{\partial^{2} \mathrm{v}}{\partial \mathrm{z}^{2}}\right)
\end{gathered}
$$

$$
\rho\left(\mathrm{u} \frac{\partial \mathrm{w}}{\partial \mathrm{x}}+\mathrm{v} \frac{\partial \mathrm{w}}{\partial \mathrm{y}}+\mathrm{w} \frac{\partial \mathrm{w}}{\partial \mathrm{z}}\right)=-\frac{\partial \mathrm{P}}{\partial \mathrm{z}}+\mu
$$

The Energy equation: 


$$
\begin{gathered}
\rho \mathrm{Cp} \quad\left(\mathrm{u} \frac{\partial \mathrm{T}}{\partial \mathrm{x}}+\mathrm{v} \frac{\partial \mathrm{T}}{\partial \mathrm{y}}+\mathrm{w} \frac{\partial \mathrm{T}}{\partial \mathrm{z}}\right)=\mathrm{k} \quad\left(\frac{\partial^{2} \mathrm{~T}}{\partial \mathrm{x}^{2}}+\right. \\
\left.\frac{\partial^{2} \mathrm{~T}}{\partial \mathrm{y}^{2}}+\frac{\partial^{2} \mathrm{~T}}{\partial \mathrm{z}^{2}}\right)
\end{gathered}
$$

where $\mathrm{u}, \mathrm{v}$, and $\mathrm{w}$ are velocities in the $\mathrm{x}, \mathrm{y}$, and $\mathrm{z}$ directions, respectively; the volumetric density viscosity in a dynamic state; $\mathrm{p}$ the stress; $\mathrm{T}$ stands for temperature; $\mathrm{Cp}$ is the fluid's heat capacity at constant pressure, and $\mathrm{k}$ is its thermal conductivity [13].

For Turbulent flow k-epsilon model was used [11].

For turbulent energy k,

$$
\frac{\partial\left(\rho u_{j} k\right)}{\partial x_{j}}=P_{k}-\beta^{*} \rho \varepsilon k+\frac{\partial}{\partial x_{j}}\left[\left(\mu+\frac{\mu_{t}}{\sigma_{k}}\right) \frac{\partial k}{\partial x_{j}}\right]
$$

For specific dissipation rates $\boldsymbol{\varepsilon}$ :

$$
\frac{\partial\left(\rho u_{j} \varepsilon\right)}{\partial x_{j}}=\alpha \frac{\varepsilon}{k} P_{k}-\beta \rho \varepsilon^{2}+\frac{\partial}{\partial x_{j}}\left[\left(\mu+\frac{\mu_{t}}{\sigma_{\omega}}\right) \frac{\partial \varepsilon}{\partial x_{j}}\right]
$$

The production of kinetic energy, $\mathrm{P}_{\mathrm{k}}$, for incompressible flows is expressed by:

$$
P_{k}=\mu_{t}\left[\frac{\partial u_{i}}{\partial x_{j}}+\frac{\partial u_{j}}{\partial x_{i}}\right] \frac{\partial u_{i}}{\partial x_{j}}
$$

\subsection{Computational methodology}

The ANSYS workbench is used to construct the model geometry and mesh, while FLUENT software is used to compute the main formulas for steady-state turbulent flow. To simulate hydrodynamic and heat transfer problems, computational fluid dynamics (CFD) is used as a volume control approach. The first step in the derivation of the flow domain in the finite volume approach is to divide it into cells, and then analyze it using the governing equations on control points on the cells. The mesh model is made up of 6,932,658 elements and was created using tetrahedral cells (see Fig. 2). The SIMPLE (Semi-Implicit Method for Pressure-Linked Equations) algorithm discretizes the convective terms in momentum and energy equations using a second-order upwind. Convergence absolute criterion is set by the continuity and momentum equations by $10^{-3}$ as for the energy equation $10^{-6}$. 


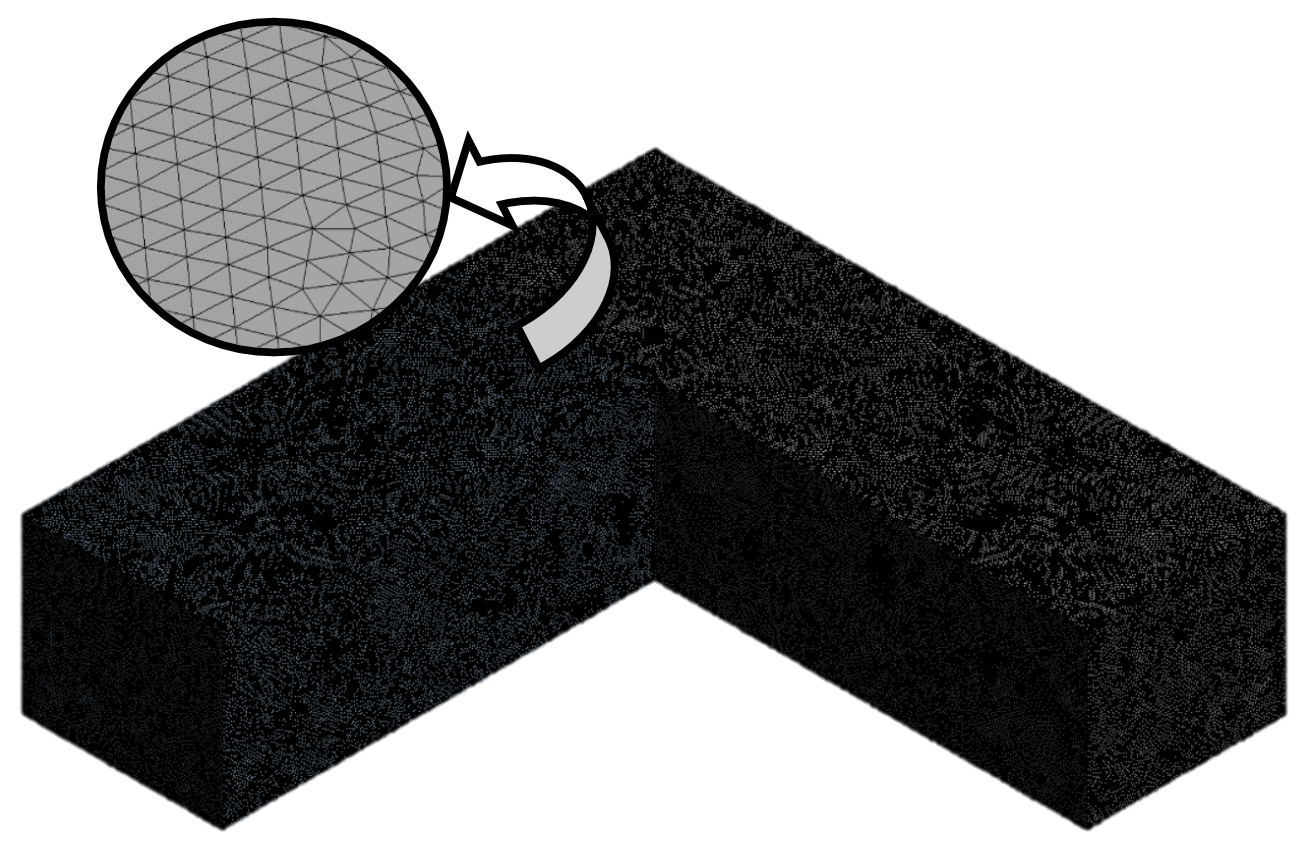

Fig. 2. The meshing of the computational model.

\section{Results and discussion}

The present section of this paper aims to demonstrate the effect of turbulence or circulation of air entering the core of the exchanger on its thermal performance through the distribution charts of velocity, the gradient of temperature, and efficiency.

Fig. 3, presents the Contour of velocity $[\mathrm{m} / \mathrm{s}$ ] for $\mathrm{Re}=12000$ on the $\mathrm{Y}-\mathrm{Z}$ plane along the cold channel only with four cases: case 1 without baffles, cases 2,3, and 4 with baffles at 45,90 and 135-degree baffle inclination respectively. Because the fluid is transported from the middle to the near-wall regimes, the emergence of longitudinal vortex flows can aid in increasing heat transfer in the square channel. The results show a high swirl with baffles at all angles inclination. At Case 3 maximum air velocity is reached $1.4 \mathrm{~m} / \mathrm{sec}$, while 0.9 and 1.1 for 45 and 135-degree inclination angles. 

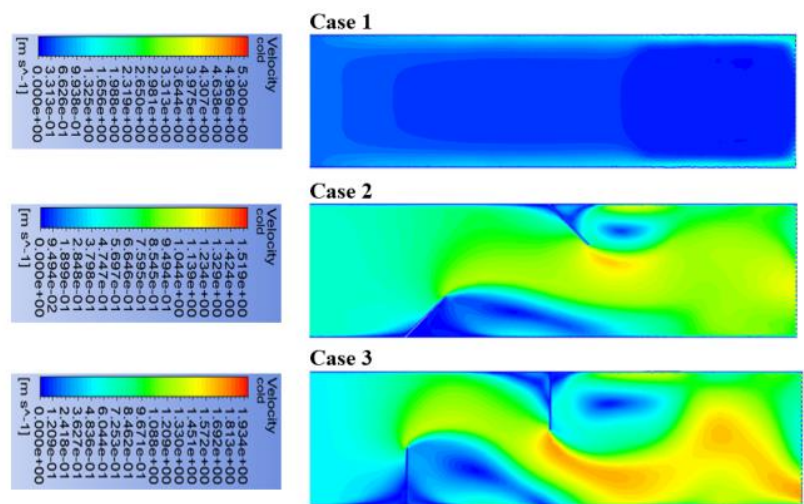

Case 3
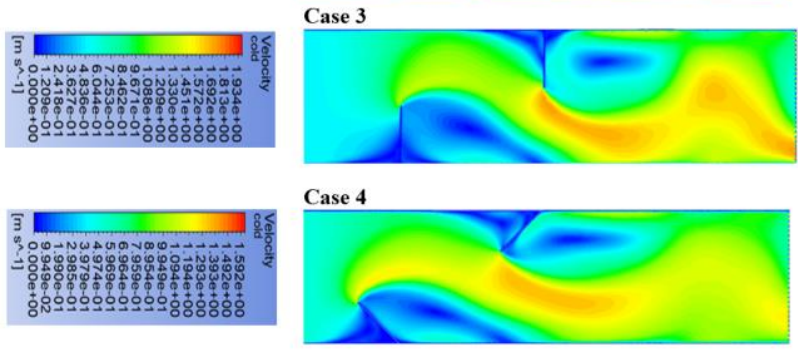

Fig. 3. The contour of velocity $[\mathrm{m} / \mathrm{s}]$ for $\mathrm{Re}=12000$ on the $\mathrm{Y}-\mathrm{Z}$ plane in the cold channel.

Fig. 4, shows the contour of velocity $[\mathrm{m} / \mathrm{s}]$ for $\mathrm{Re}=12000$ on the $\mathrm{X}-\mathrm{Y}$ plane in the hot channel only with four cases: case 1 without baffles, cases 2,3, and 4 with baffles at 45,90 and 135-degree baffle inclination respectively. The flow is accelerated and redirected near the baffles as the streamlines are compared at different baffle inclination angles. As the baffle approaches, the fluid is accelerated in the first zone, directly upstream of the two baffles, and reaches a velocity in the axial direction; the streamlines of fluid are deflected. The second zone, which is positioned between the end (the top) of each baffle and the channel wall, is characterised by relatively high velocities, which can reach values of the order of 440 percent of the entrance velocity. The results confirm there is a clear effect of the inlet air vortices on the gradient then the thermal performance inside the core will be enhanced. The results show a high swirl with baffles at all angles inclination. At Case 3 max air velocity reaches $1.4 \mathrm{~m} / \mathrm{sec}$, while 0.9 and 1.1 for 45 and 135 -degree inclination angles. 

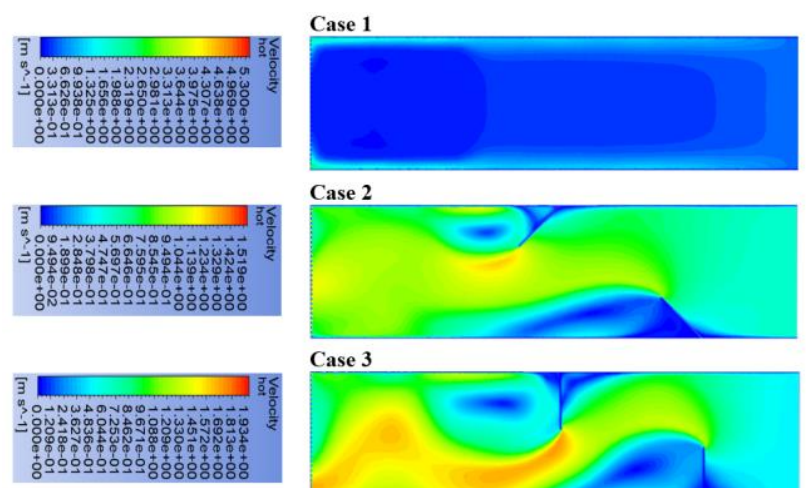

Case 3
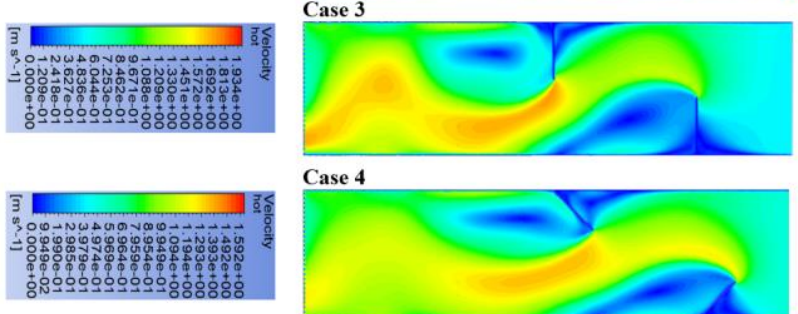

Case 4

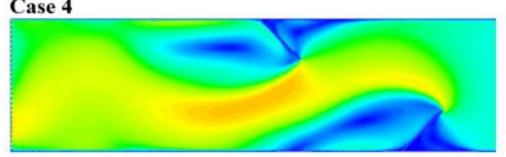

Fig. 4. The contour of velocity $[\mathrm{m} / \mathrm{s}]$ for $\mathrm{Re}=12000$ on the $\mathrm{X}-\mathrm{Y}$ plane in the hot channel.

Fig. 5, presents the Contour of temperature [k] for $\mathrm{Re}=12000$ on $\mathrm{Y}-\mathrm{Z}$ plane in recovery core when fixed baffles inside the inlet cold channel with different angle inclination 45,90 and 135 degrees respectively. The value of the largest temperature gradient appears behind the core's interface wall as a result of variations in the direction of the flow caused by the baffles. It is obvious that as a result of the facilitated heat exchange, temperatures for high velocities drop significantly..

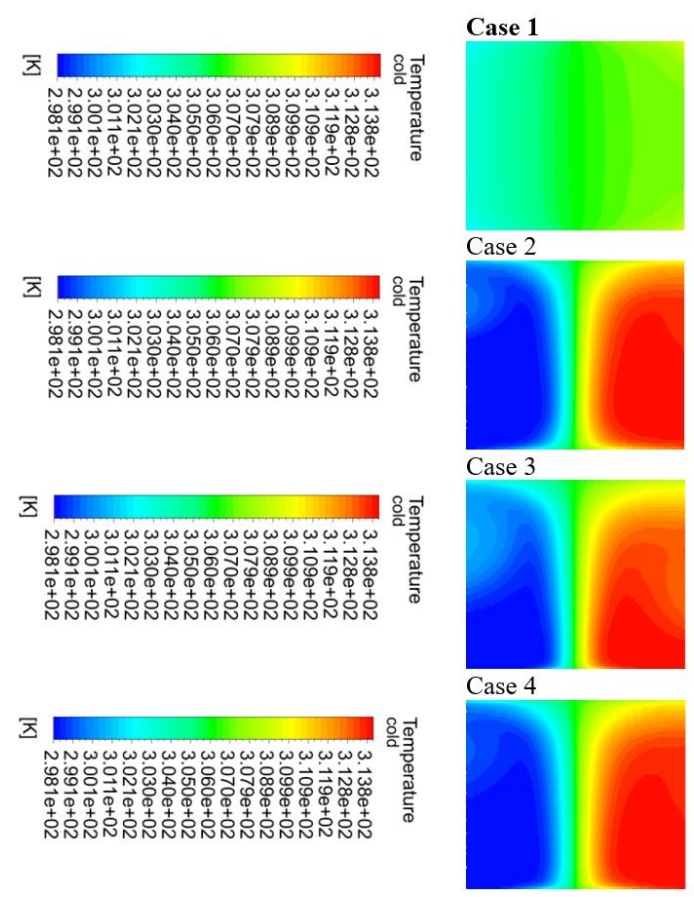


Fig. 5. The contour of temperature $[\mathrm{k}]$ for $\mathrm{Re}=12000$ on the $\mathrm{Y}-\mathrm{Z}$ plane in the core.

Fig. 6, presents the temperature gradient inside the core of the recovery at the hot side as the result of variation of baffles inclination inside the hot channel. Also, the results show the high effect of air swirl on the thermal perforation especially at angles 45 and 135 degrees. The results gave a higher effect for the baffle at an angle of 45 degrees more than the others.

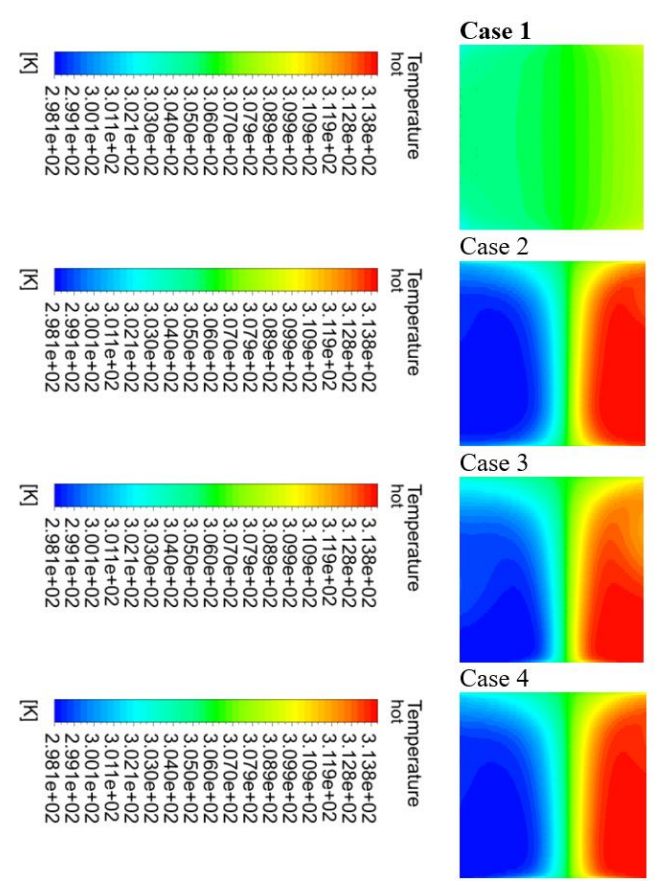

Fig. 6. The contour of temperature $[\mathrm{k}]$ for $\mathrm{Re}=12000$ on the $\mathrm{X}-\mathrm{Y}$ plane in the core.

Figure 7 depicts the fluid temperature profiles for a Reynolds number of 12,000 at various points along the hot and cold channel centerlines. The cold channel's inlet temperature is $298.15 \mathrm{k}$ in all cases, but the outlet temperature varies between $308.4 \mathrm{k}$ and $312.6 \mathrm{k}$. The highest temperature was found in case 2, which was $312.6 \mathrm{k}$. This means that the baffle has a temperature enhancement effect with a temperature increase of $4.2 \mathrm{k}$. However, in the hot channel, the inlet temperature is $314.15 \mathrm{k}$, and the heat exchanger's outlet temperature varies from $303.87 \mathrm{k}$ to $299.74 \mathrm{k}$, with the lowest temperature in case 2 and the highest in case 1 . In terms of heat transfer, this means that case 2 is the best angle. 

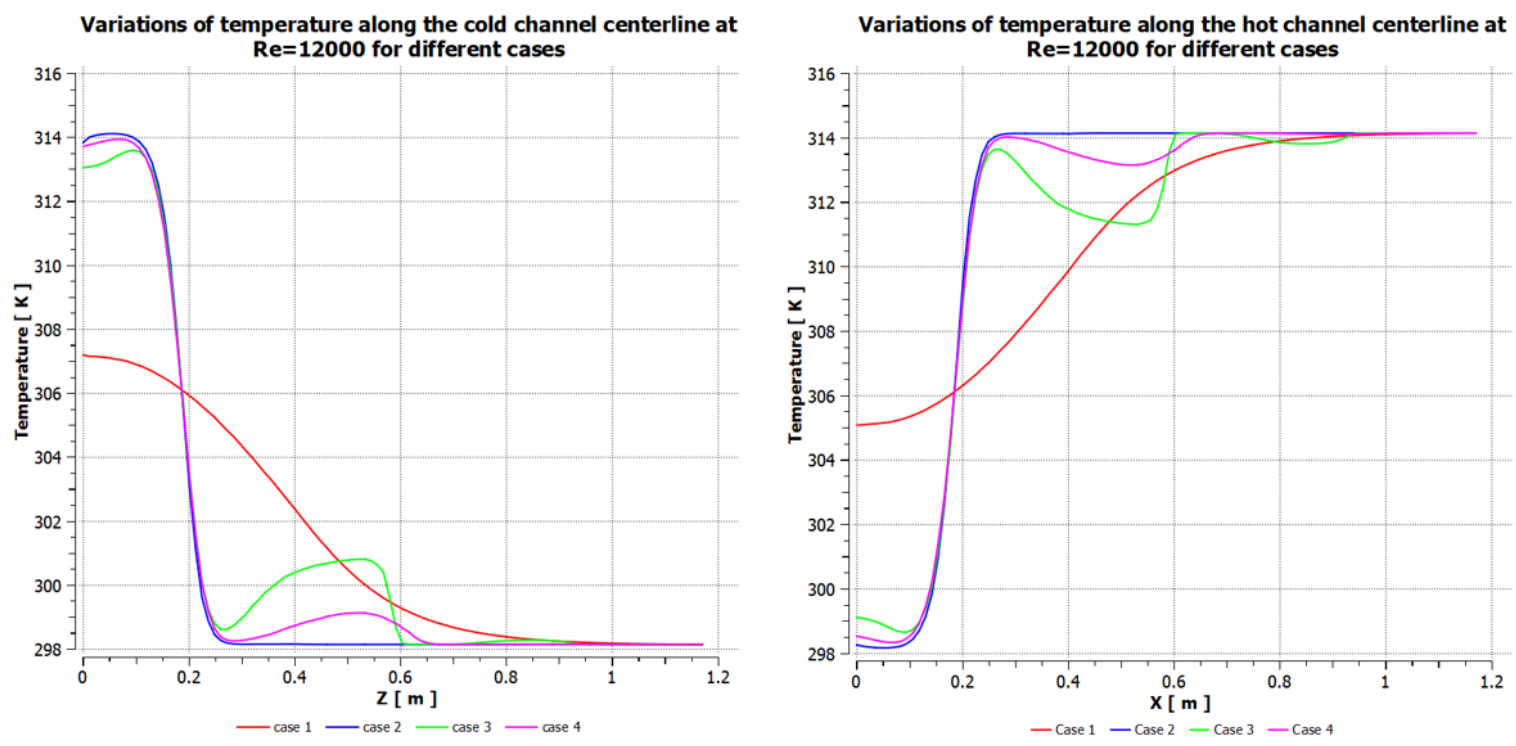

Fig. 7. Temperature variation along the hot and cold channel centerlines at $\mathrm{Re}=12000$ for various instances.

Fig. 8, presents the average velocity profile along the hot and cold channel at constant Reynold number $(\mathrm{Re}=12000)$ for various cases. For both the hot and cold channels, the inlet velocity was $0.51 \mathrm{~m} / \mathrm{s}$. When placing the baffles, we noticed an increase in velocity along the channels, which increased by $0.2 \mathrm{~m} / \mathrm{s}$. Case $390^{\circ}$ ) yielded the highest average velocity, which was $1.4 \mathrm{~m} / \mathrm{s}$.
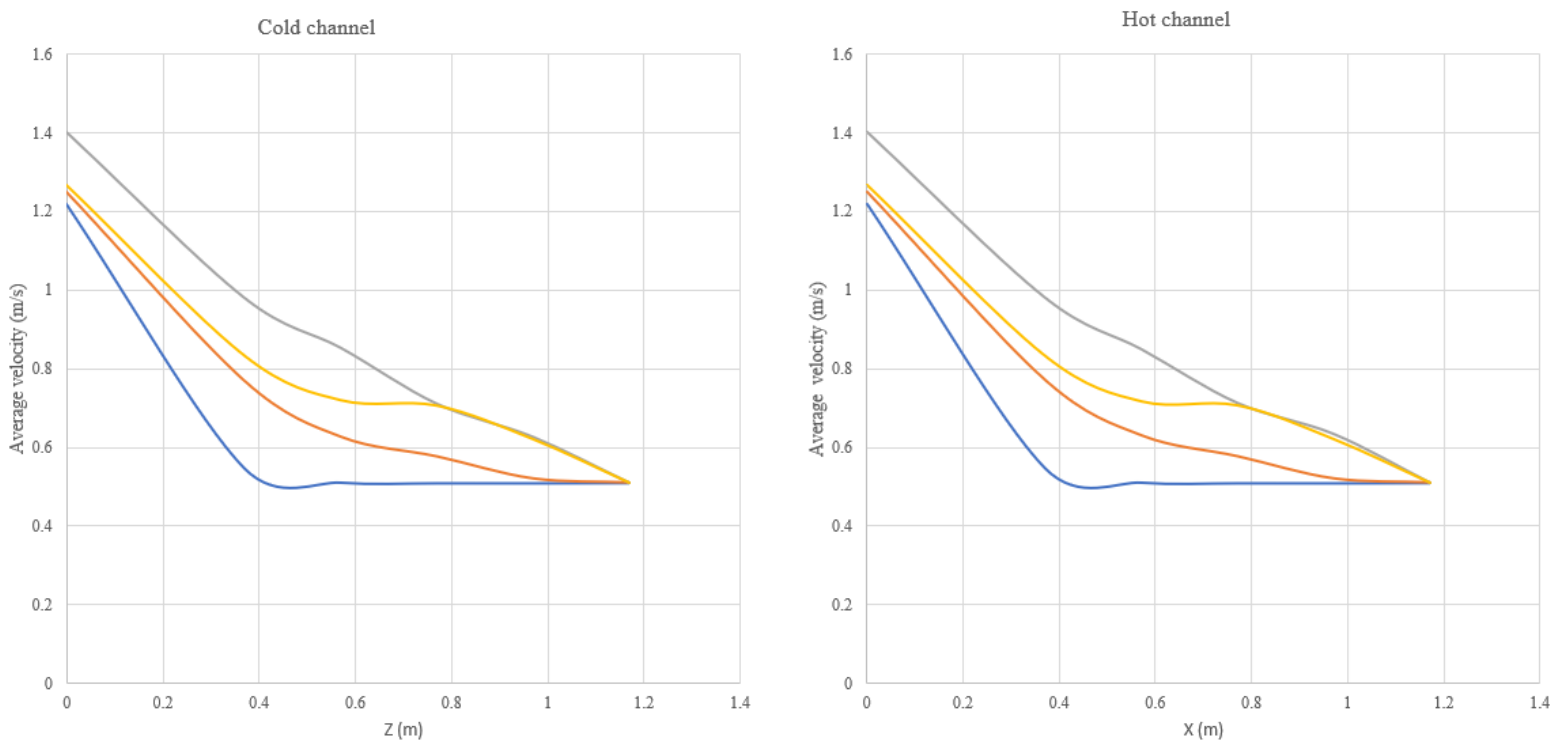

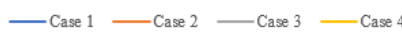

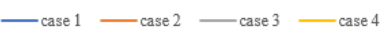


Fig. 8. Variation of average velocity along the hot and cold channel at $\mathrm{Re}=12000$ for different cases.

For various situations with $\mathrm{Re}=12000$, Fig. 9 depicts the pressure drop fluctuation along the hot and cold channel at the centerlines level. As expected, as the angle of the baffles is increased, the pressure reduces. The pressure drops values range from 16.34 pascal, in case 1 , to 18 pascals in case 4 . Also, the results show the high-pressure drop occurs in case $4\left(135^{\circ}\right)$. In case 3 , we observe a decrease in pressure drop near the first and second baffles due to high air vortices.

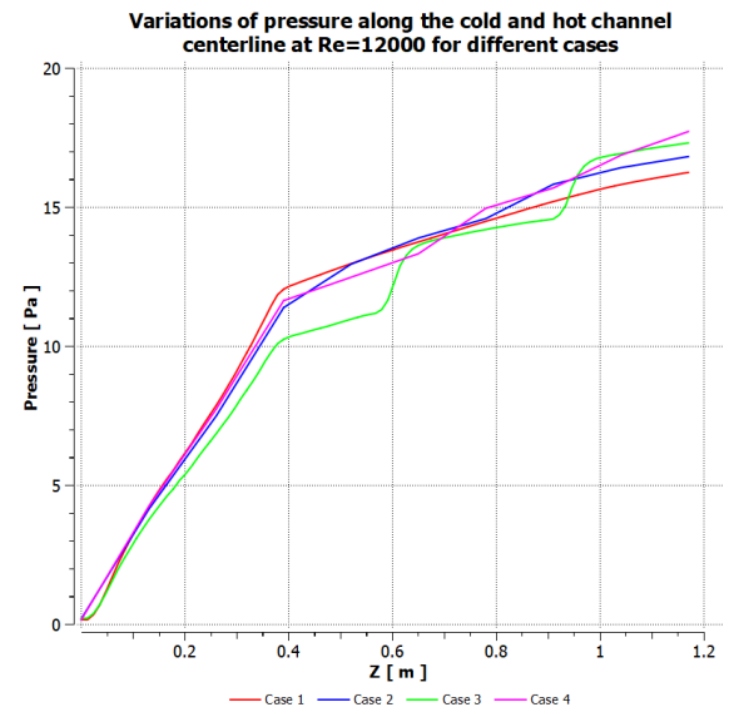

Fig. 9. Variation pressure along the hot and cold channel centerline at $\mathrm{Re}=12000$ for different cases.

Fig. 10, illustrates the overall recovery system effectiveness in four cases at constant Re. The results notice the increase in effectiveness by increasing the inclination of angle. The results turn out that the effectiveness increased by $22 \%$ when the baffles were applied to the channel. It was found that the most effective angle was 45 degrees (case 2), with a 90 percent effectiveness. Furthermore, a review of our numerical results on axial velocity and temperature 
fields for the entire region analysed reveals that the recovery effectiveness is linked to circulation velocity..

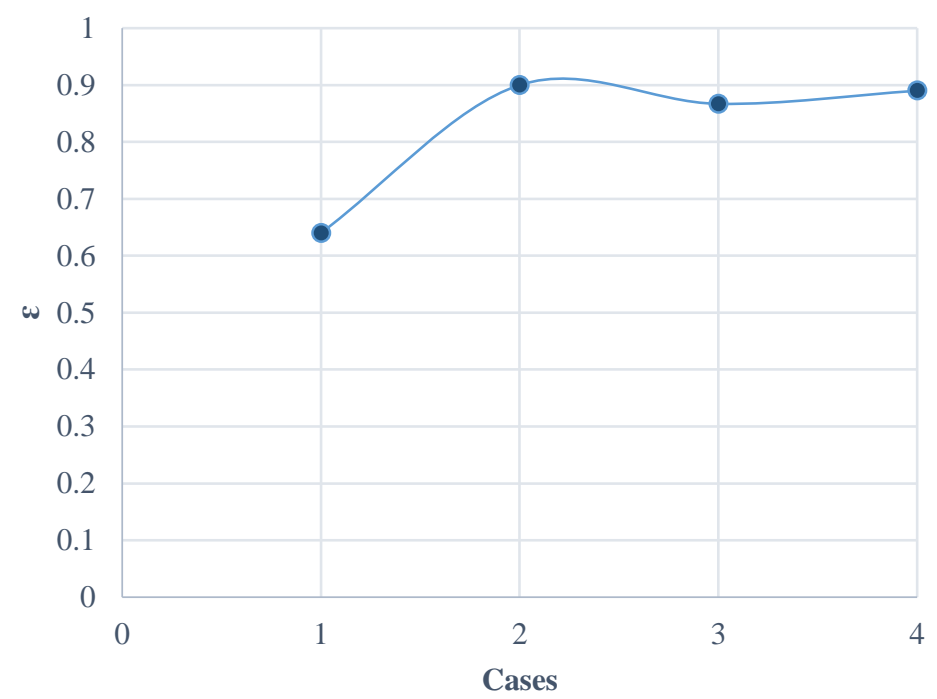

Fig. 10. Effectiveness for different cases at constant $\mathrm{Re}=12000$.

\section{Verification}

Verification was carried out to ensure that the current numerical model is working properly through a comparison between the numerical of the current model and the experimental for the same model used. By making sure of its current results and applying the same experimental operating conditions in terms of flow, inlet temperature for the cold pass $\left(25.1^{\circ} \mathrm{c}\right)$ and inlet temperature for hot pass $\left(41.6^{\circ} \mathrm{c}\right)$, volume flow rate $\left(139 \mathrm{~m}^{3} / \mathrm{h}\right)$, and the number of passes $(56)$. dimensions of core, length $(370 \mathrm{~mm})$, width $(370 \mathrm{~mm})$, height $(320 \mathrm{~mm})$, and thickness $(0.6 \mathrm{~mm})$. There was a strong correlation between the obtained results and the experimental data, as shown in Fig. 11. The largest relative error between the numerical current work and the experimental current work is approximately 6.4 percent, as can be observed. Hence the comparison can be considered reasonable. This indicates the validity of the numerical model used in our current research. 


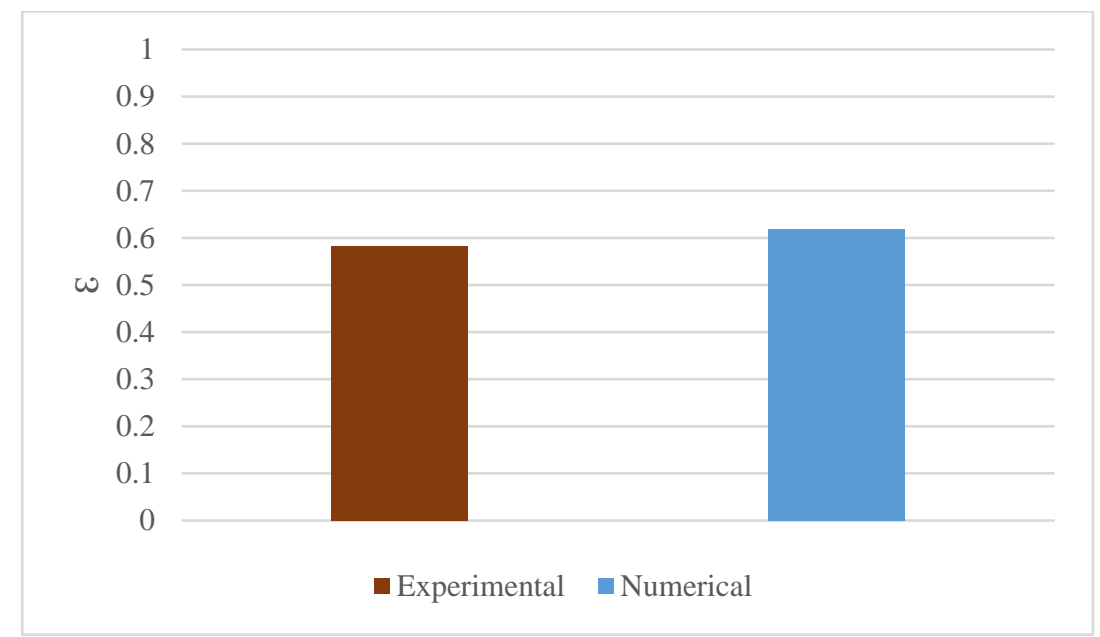

Fig. 11. Effectiveness tests with the change of numerical results and experimental results.

\section{Conclusions}

The heat transfer in an HRV with two baffles mounted to the top and bottom walls of the hot and cold duct at various angles is investigated numerically in this work.. The main conclusions of this study are drawn as follows:

1. When fixed baffles are mounted within the channel at a constant Reynolds number, the effectiveness increases by $35 \%$. While maximum effectiveness is found about 90 percent for the $45^{\circ}$ baffles angle.

2. The pressure drop increases with the increase in the baffles's angle, and the results notice the highest pressure drop occurs in case 4. At its maximum rated design flow, the pressure drop did not exceed $130 \mathrm{~Pa}$, indicating that the thermal output could be improved.

3. In terms of temperature difference, case 2 shows enhancement influences on heat transfer performance.

4. Finally, Maximum velocity is found in case 3 where the velocity is about $1.4 \mathrm{~m} / \mathrm{s}$ axial that found recovery effectiveness is related to the velocity of circulations.

\section{References}

[1] F. L. ASSUNCAO, "A NUMERICAL PERFORMANCE ANALYSIS OF HEAT RECOVERY VENTILATORS WITH STAGGERED-BAFFLE CHANNELS,” Angew. Chemie Int. Ed., 2016.

[2] H. Han, Y. Choo, and Y. Kwon, "An experimental study on the effect of outdoor temperature and humidity conditions on the performance of a heat recovery ventilator," Proc. Clima, Well Being Indoors, 2007.

[3] Y. Menni, M. Ghazvini, H. Ameur, M. H. Ahmadi, M. Sharifpur, and M. Sadeghzadeh, "Numerical calculations of the thermal-aerodynamic characteristics in a solar duct with multiple 
V-baffles,” Eng. Appl. Comput. Fluid Mech., 2020.

[4] K. H. Ko and N. K. Anand, "Use of porous baffles to enhance heat transfer in a rectangular channel," Int. J. Heat Mass Transf., 2003.

[5] H. Benzenine, R. Saim, S. Abboudi, and O. Imine, "Numerical analysis of a turbulent flow in a channel provided with transversal waved baffles," Therm. Sci., 2013.

[6] D. Saad and M. S. Kassim, "Effect of Baffles Geometry on Heat Transfer Enhancement inside Corrugated Duct,” Int. J. Mech. Eng. Technol., 2019.

[7] W. M. Abed, "Numerical Study Of Laminar Forced Convection Heat Transfer And Fluid Flow Characteristics In A Corrugated Channel Nomenclature : List of symbols," 2010.

[8] Y. Menni and A. Azzi, "Numerical analysis of thermal and aerodynamic fields in a channel with cascaded baffles," Periodica Polytechnica Mechanical Engineering, vol. 62, no. 1. pp. 16-25, 2018, doi: 10.3311/PPme.10613.

[9] X. Tang and D. Zhu, "Experimental and numerical study on heat transfer enhancement of a rectangular channel with discontinuous crossed ribs and grooves," Chinese J. Chem. Eng., 2012.

[10] Y. Menni, A. J. Chamkha, and A. Azzi, "Fluid flow and heat transfer over staggered + shaped obstacles," Journal of Applied and Computational Mechanics. 2020.

[11] P. Dutta and A. Hossain, "Internal cooling augmentation in rectangular channel using two inclined baffles," Int. J. Heat Fluid Flow, 2005.

[12] H. Ameur, "Effect of corrugated baffles on the flow and thermal fields in a channel heat exchanger," J. Appl. Comput. Mech., 2020.

[13] "Versteeg H., An Introduction to Computational Fluid Dynamics - The Finite Volume Method, 1995.pdf.". 